\title{
Boredom proneness, political orientation and adherence to social-distancing in the
}

pandemic.

Nick Brosowsky, Wijnand Van Tilburg, Abigail Scholer, James Boylan, Paul Seli, \& James Danckert

Nicholaus P. Brosowsky ${ }^{1}$, Wijnand Van Tilburg ${ }^{2}$, Abigail A. Scholer ${ }^{3}$, James Boylan ${ }^{3}$, Paul Seli $^{1}, \&$ James Danckert ${ }^{3}$

Affiliations:

1. Department of Psychology and Neuroscience, Duke University

417 Chapel Drive

Durham, NC 27708, USA

2. Department of Psychology

Essex University

Wivenhoe Park

Colchester, C04 3SQ, United Kingdom

3. Department of Psychology

University of Waterloo

200 University Avenue West

Waterloo, ON, N2L 3G1

CANADA

Accepted for publication in Motivation and Emotion, May, 2021 


\begin{abstract}
Research recently showed that boredom proneness was associated with increased social distancing rule-breaking in a sample collected early in the COVID-19 pandemic. Here we explore data collected early in the pandemic to examine what factors might drive this relation. We focus on political affiliation. Given the functional account of boredom as a call to action, we hypothesized that this urge to act may drive individuals towards outlets replete with symbolic value (e.g., ideology, identity). In addition, given the politicization of some social distancing rules (e.g., mask wearing), we explored whether those who adhere to strong political ideologies — particularly conservative ideologies_-would be more likely to rule-break. Moderation analyses indicated that boredom proneness and social (but not fiscal) conservatism were indeed predictive of rule-breaking. These results highlight the need for both clear messaging emphasizing the strength of communal identity and action (i.e., that "We are all in this together") and for interventions that emphasize shared collective values in contexts that appeal directly to social conservatives.
\end{abstract}

Key words: COVID-19, boredom proneness, political ideology, rule-breaking 


\section{Introduction}

Boredom is ubiquitous in human existence (Chin et al., 2017; Eastwood et al., 2012). The in-the-moment feeling of boredom - i.e., state boredom - is unpleasant (Smith \& Ellsworth, 1985), and many of the consequences associated with both state boredom and trait boredom proneness spell personal or social trouble, from higher rates of depression (Eastewood et al., 2012) and sadistic aggression (Pfattheicher et al., 2020), to increased risk-taking (K1lıç, Van Tilburg, \& Igou, 2020), to name just a few.

Although trait boredom proneness is commonly associated with negative outcomes, the momentary experience of state boredom is not inherently dysfunctional. Like other negative emotions (Carver \& Scheier, 1990), state boredom serves a self-regulatory purpose, signaling disengagement from our environs (Eastwood et al., 2012). State boredom may arise as a function of monotony, evaluations that what we are doing lacks meaning, or some combination of these and other situational factors (Daschmann et al., 2011; Pawlak et al., 2020; Pekrun, 2006; Van Tilburg \& Igou, 2011; Westgate \& Wilson, 2018). Such influences of these factors may well be context specific, with recent research demonstrating distinct trajectories of boredom based on individual factors and learning context, in a small sample of students learning English as a second language (Pawlak et al., 2020). Whatever the circumstantial causes of state boredom, the implied need is one of action (Elpidorou, 2014). As a case in point, Control-Value Theory (Pekrun, 2006) notes that state boredom features in achievement settings (e.g., academic learning; Pekrun, Goetz, Daniels, Stupnisky, \& Perry, 2010). This theory proposes that state boredom arises when an activity is appraised as featuring both low levels of perceived control (e.g., the individual feels that they have a low capacity to change the situation) and low value (e.g., the task appears irrelevant to one's goals). Within this framework, state boredom is 
considered an emotion detrimental to performance and persistence in one's current activity (Pekrun, Hall, Goetz, \& Perry, 2014; Tulis \& Fulmer, 2013). When bored we seek actions to satisfy our need to be engaged - to break the monotony and add meaning where the current circumstance is lacking.

This desire to engage in purposeful actions when bored leads to a conundrum for those high in trait boredom proneness: the recognition of the need to act, coupled with a failure to launch into anything that would satisfy that need (Danckert, 2019; Moynihan et al., 2021; Mugon et al., 2018). Certainly, for the trait boredom prone, there are many associated ills indicative of maladaptive action choices, from increased risk-taking and impulsivity (Dahlen et al., 2004; Kılıç et al., 2020), to substance abuse (Biolcati et al., 2018). These maladaptive responses may satisfy another need signaled by state boredom - the need to re-establish one's sense of agency (Danckert, 2019; Elpidorou, 2018). When bored, we are acutely aware of the fact that we are failing to engage with the world effectively. Our desire to avoid boredom may be borne of our need to experience agency (Kahn, 2018; Pekrun, 2006).

During the COVID-19 pandemic, we have at times been forced to live with constraints on our lives that explicitly diminish our sense of agency and are fertile grounds for feelings of state boredom (Boylan et al., 2020; Caci et al., 2020; Chao et al., 2020; Yan et al., 2020). One early study of the Italian experience asked people to report what they felt were the most negative outcomes of social isolation (Barari et al., 2020). The most prominent response was a 'lack of freedom' (i.e., diminished agency), followed by in-the-moment feelings of boredom. Alternatively, the negative effects of state boredom during lockdown were lower among those who maintained a strong sense of control over their actions (Caci et al., 2020). Thus, it is not inevitable that constraints on our agency will ultimately lead to maladaptive action choices. As a 
case in point, one French man ran a marathon while in social isolation —on his balcony $(\mathrm{CNN}$, March 2020)!

Initial results from research conducted during the early stages of the pandemic showed that those high in trait boredom proneness were more likely to break the rules of social distancing (Boylan et al., 2020; Wolff et al., 2020). In terms of a threat to one's sense of agency, those who experience boredom with greater intensity and frequency are more likely to seek activities that enable them to re-establish agency and a sense of meaning (Kahn, 2018; Tam et al., in press), even if those actions are counter to the demands of social isolation.

The notion that in-the-moment feelings of boredom represent a call to action implies that the state itself does nothing to determine which actions might best address the call. An additional factor-perception of meaningful behavior-likely has a strong influence on action choice (Van Tilburg \& Igou, 2011; Westgate \& Wilson, 2018). Van Tilburg and Igou (2019) propose that within the cultural landscape that humans occupy, the basic expression of state boredom's call to action manifests in the pursuit of behavior laden with symbolic value (e.g., ideology, identity), provided that such opportunities are readily available. Research suggests that the actions following experimentally induced state boredom express themselves in behaviors that offer people a sense of meaning. For example, higher levels of state boredom commits people more strongly to their national ingroup at the expense of members of a threatening outgroup (Van Tilburg \& Igou, 2011), heightens willingness to support charitable causes (Van Tilburg \& Igou, 2017), and triggers elaborate nostalgic reverie (Van Tilburg et al., 2013). Each of these responses offers a sense of meaning or purpose (Klein, 2017; Routledge et al., 2011; Spears et al., 2004) and are established remedies to meaning-threats (Heine, Proulx, \& Vohs, 2006; Routledge et al., 
2008). A sense of meaning, in turn, alleviates feelings of state boredom (Fahlman et al., 2009; Van Tilburg et al., 2019).

Boredom and boredom proneness also show important relations to one's adherence to political affiliations (Van Tilburg \& Igou, 2016). When people are induced into the state of boredom they report stronger adherence to political extremes at either end of the political spectrum. But it is also true that those prone to experiencing situational boredom report holding more extreme political beliefs — again, at either end of the political spectrum—a relationship statistically mediated by the search for life meaning. This may be, in part, because political ideology offers solace in the face of meaning-threats (e.g., McGregor, Prentice, \& Nash, 2013), perhaps because such ideologies tend to offer guidance about one's role and values within society. Furthermore, political ideologies may help retain or restore a sense of agency. Research shows that conservative ideology, in particular may help people deal with uncertainty (Jost et al., 2007; cf. Greenberg \& Jonas, 2003) by advocating for the (certain) status quo (Jost \& Amodio, 2012).

Thus, the bored may seek solace in their political ideologies. What association can be expected to emerge between boredom proneness and political ideology? On the one hand, Van Tilburg and Igou (2016) found that—in an Irish sample—-boredom proneness corresponded with more polarized political orientations. On the other hand, research with predominantly US samples suggests that especially conservative ideologies may offer solace when faced with a lack of meaning or uncertainty (Jost et al., 2007). Interestingly, adherence to recommendations such as mask-wearing and social distancing has become politicized over the course of the pandemic (Hart et al., 2020). Within the USA, it appears that those who oppose regulations such as maskwearing tend to hue towards the conservative end of the political spectrum (Corpuz et al., 2020). 
If it is the case that boredom proneness prompts a drive towards asserting one's identity and values through a variety of means (e.g., bolstering political ideology; Van Tilburg et al., 2019), then we might expect that boredom proneness predicts the breaking of COVID-19 restrictions especially among those whose political affiliation comes with skepticism towards such restrictions - those who hold more conservative political views. Accordingly, we explored whether boredom proneness would be more strongly associated with rule-breaking among US conservatives than liberals. To be clear, this proposed pathway assumes that the boredom prone experience the state of boredom more frequently and intensely, an assumed truism borne out by recent research (Tam et al., 2021). The logic here is as follows: the constraints imposed by the social distancing and lockdown measures of the pandemic likely lead to increased feelings of state boredom (e.g., Barari et al., 2020), which in turn will be felt more acutely among the highly boredom prone (Tam et al., 2021). These same restrictions are also likely to lead to a perceived threat to personal identity, perhaps most pointedly for those who adhere to conservative ideologies (Corpuz et al., 2020). Both state boredom and trait boredom proneness are associated with a need to seek meaning in one's life (Fahlman et al., 2009; Tam et al., 2021; Van Tilburg \& Igou, 2011, 2016). This desire can be satisfied by establishing or strengthening one's personal affiliations. In the context of the COVID-19 pandemic, this was hypothesized to result in increased rule-breaking, particularly among the highly boredom prone who hold more strongly to conservative political ideologies. We tested this hypothesis in data we collected during the lockdown imposed to curb the first wave of the pandemic (Boylan et al., 2020). 


\section{Participants}

Our sample has been described elsewhere (Boylan et al., 2020). Participants were recruited via Amazon's Mechanical Turk and to be eligible had to have a 95\% HIT acceptance rate and have completed $>500$ HITs. The sample consisted of 993 people. Data from 69 participants were removed as they were identified as non-serious responders (Boylan et al., 2020). The final sample consisted of 924 participants ( 386 female, 530 male, 8 responding as “other” gender; mean age $=37.70$ years, $S D=11.25$; range=18-77; see Boylan et al., for breakdown of ethnicities). The sample came primarily from the United States $(n=913)$ with data collected between April $28^{\text {th }}$ and May $2^{\text {nd }}$ of 2020. Reliability analyses were conducted with participants set as items, and participants with item-total correlations $>.20$ removed as nonserious responders (overall participant reliability; Cronbach's $\alpha=.994$; Boylan et al., 2020). We used several attention checks to ensure the integrity of our data (see Boylan et al., 2020 for details).

\section{Surveys}

Participants completed a large survey of which a subset is reported here. To assess political affiliation, we asked people to rate their political beliefs on a 7-point scale with respect to two domains - economic and social issues (e.g., Crowson, 2009). ${ }^{1}$ We used five anchor points: "very liberal" and "liberal" occupying responses 1 and 2, "centrist" occupying response 4, and "conservative" and "very conservative" occupying responses 6 and 7. Higher scores represent affiliation with stronger conservative ideologies.

\footnotetext{
${ }^{1}$ We used single items over full length scales (e.g., Henningham, 1996) for practical reasons (i.e., to keep completion time for the whole survey set reasonable).
} 
We assessed boredom proneness using the shortened boredom proneness scale (SBPS;

Struk et al., 2017), an 8-item scale derived from Farmer and Sundberg's (1986) original 28-item scale (example item: "I don't feel motivated by most things that I do.”). Responses were measured on a 7-point Likert scale ranging from strongly agree to strongly disagree, with higher scores indicating higher levels of trait boredom proneness. Struk and colleagues (2017) report good construct validity and internal consistency (Cronbach's alpha of .88). Cronbach's alpha for the current sample was .93. Participants were asked to refer to typical experiences of boredom as experienced prior to the pandemic.

\section{Rule-breaking Questions}

We assessed compliance with social-distancing requirements during the COVID-19 pandemic with nine questions (Table 1). Participants were asked to consider their behavior over the preceding week. Cronbach's alpha for these questions in the current sample was .86. To determine whether the data was suitable for subjecting to principal components analysis we employed several well-recognized criteria. It was first determined that all inter-item correlations were at least .3 or greater suggesting reasonable factorability. Next, the Kaiser-Meyer-Olken measure of sampling adequacy was .85 , well above the commonly recommended value of .6. Finally, Bartlett's test of sphericity was significant $(\chi 2(21)=2912.72, p<.05)$ indicating sufficient significant correlations within the data to enable a principal components factor analysis. Results of this analysis revealed a single latent component accounting for $54.99 \%$ of the variability in seven of the nine questions (eigenvalue=3.84; Table 1). The component had high negative loadings on the extent to which individuals practiced social distancing, the number of hours spent at home, and high positive loadings on frequency of in-person social visits, 
Table 1. Rule-breaking questions and factor loadings.

\begin{tabular}{lcc}
\hline Questions & Scale & Loadings \\
\hline $\begin{array}{l}\text { To what extent are you practicing social } \\
\text { distancing? }\end{array}$ & -.60 \\
$\begin{array}{l}\text { On average, how many hours of the day are } \\
\text { you spending in your household (including } \\
\text { your garage or yard but not going into the } \\
\text { neighborhood or other public spaces)? }\end{array}$ & -.59 \\
$\begin{array}{l}\text { How frequently have you gone out for in- } \\
\text { person social visits? }\end{array}$ & $1-24$ \\
$\begin{array}{l}\text { How frequently do you go out to shop in- } \\
\text { person? }\end{array}$ & $1-5$ (not at all to \\
$\begin{array}{l}\text { How many times have you intentionally broken } \\
\text { social distancing protocols? (best guess; not } \\
\text { counting people who live with you in your } \\
\text { household) }\end{array}$ & Free Numerical Entry \\
$\begin{array}{l}\text { How many people have come within 6 feet of } \\
\text { you over the last week (best guess, other than }\end{array}$ \\
people who live with you in your household)? \\
$\begin{array}{l}\text { In the past week, how many social gatherings } \\
\text { have you had at your home (i.e., gatherings } \\
\text { with people other than those with whom you } \\
\text { live)? }\end{array}$
\end{tabular}

Correlation with

Not included in rule-breaking component

component

$\begin{array}{lcc}\text { How many days have you spent in isolation? } & \text { Free Numerical Entry } & .39 \\ \text { To what extent are you washing your hands } & 1-4 \text { (not at all - very } & .11 \\ \text { with soap and water in response to the COVID- } & \text { much) } & \\ 19 \text { pandemic? } & \end{array}$

shopping, intentionally breaking social-distancing rules, and on allowing more people outside of one's household to come within close proximity. Thus, we labelled this component "COVID-19 
rule-breaking." Handwashing and the number of days spent in isolation did not load on this component (Table 1). We extracted individual scores for the COVID-19 rule-breaking component using the regression method and treated it as the key outcome variable. Higher scores on this composite indicate poorer social-distancing and rule-compliance (i.e., increased rulebreaking).

\section{Data Analysis}

We first examined the zero-order correlations between political affiliation, trait boredom proneness, and COVID-19 rule-breaking. Next, to determine whether political affiliation and boredom proneness predicted different levels of rule-breaking, we conducted a hierarchical regression. Given that prior research shows consistent relations between boredom proneness, age, and gender (Giambra et al., 1992; Isacescu et al., 2017), these factors (age and gender) were entered into the model first. We expected age would negatively predict COVID-19 rule-breaking. That is, given that boredom proneness declines with age (Giambra et al., 1992; Isacescu et al., 2017), it stands to reason that rule-breaking should also decrease as boredom proneness diminishes. We expected gender to positively predict COVID-19 rule-breaking such that females (who tend towards lower boredom proneness) should better adhere to social distancing protocols than males (who tend towards higher boredom proneness; e.g., Isacescu et al., 2017). Boredom proneness was added in the second step and economic and social political views were added simultaneously in the third step. To be explicit, we are assuming that those high in boredom proneness also experience the state more frequently and intensely (Tam et al., 2021), despite the fact that we do not directly measure this. In other words, we are hypothesizing that it is in-themoment feelings of boredom that function as the true mechanism underlying the moderation of 
the relation between political ideology and rule-breaking, with trait boredom proneness standing in as a proxy for state boredom.

\section{Results}

Descriptive statistics and bivariate correlations are shown in Table 2. Trait boredom proneness was positively associated with political affiliation for both social and fiscal issues. Direct contrast of these relationships using z-scores (DeCoster, 2007) showed that the relation between boredom proneness and social conservatism was significantly stronger than the relation between boredom proneness and fiscal conservatism $(z=3.39, p<0.001)$. Rule-breaking was also positively associated with political affiliation; those expressing stronger conservative views were more likely to break the rules of social distancing (Figure 1). Contrasting the relation between social and fiscal conservative views indicated that the relation was stronger for social conservative views and rule-breaking $(z=5.59, p<0.001)$.

Table 2. Summary of descriptive statistics and bivariate correlations.

\begin{tabular}{|c|c|c|c|c|c|c|}
\hline & Mean & SD & 1. & 2. & 3. & 4. \\
\hline 1. BPS & 2.87 & 1.43 & - & $0.53 *$ & $0.16^{*}$ & $0.09 *$ \\
\hline 2. Rule-breaking & 0.00 & 1.00 & & - & $0.36^{*}$ & $0.25 *$ \\
\hline Political Views & & & & & & \\
\hline 3. Social & -0.55 & 1.98 & & & & $0.80 *$ \\
\hline 4. Economic & -0.19 & 1.93 & & & & - \\
\hline
\end{tabular}

Note: BPS=Boredom Proneness Scale; ${ }^{*} p<0.05$ 

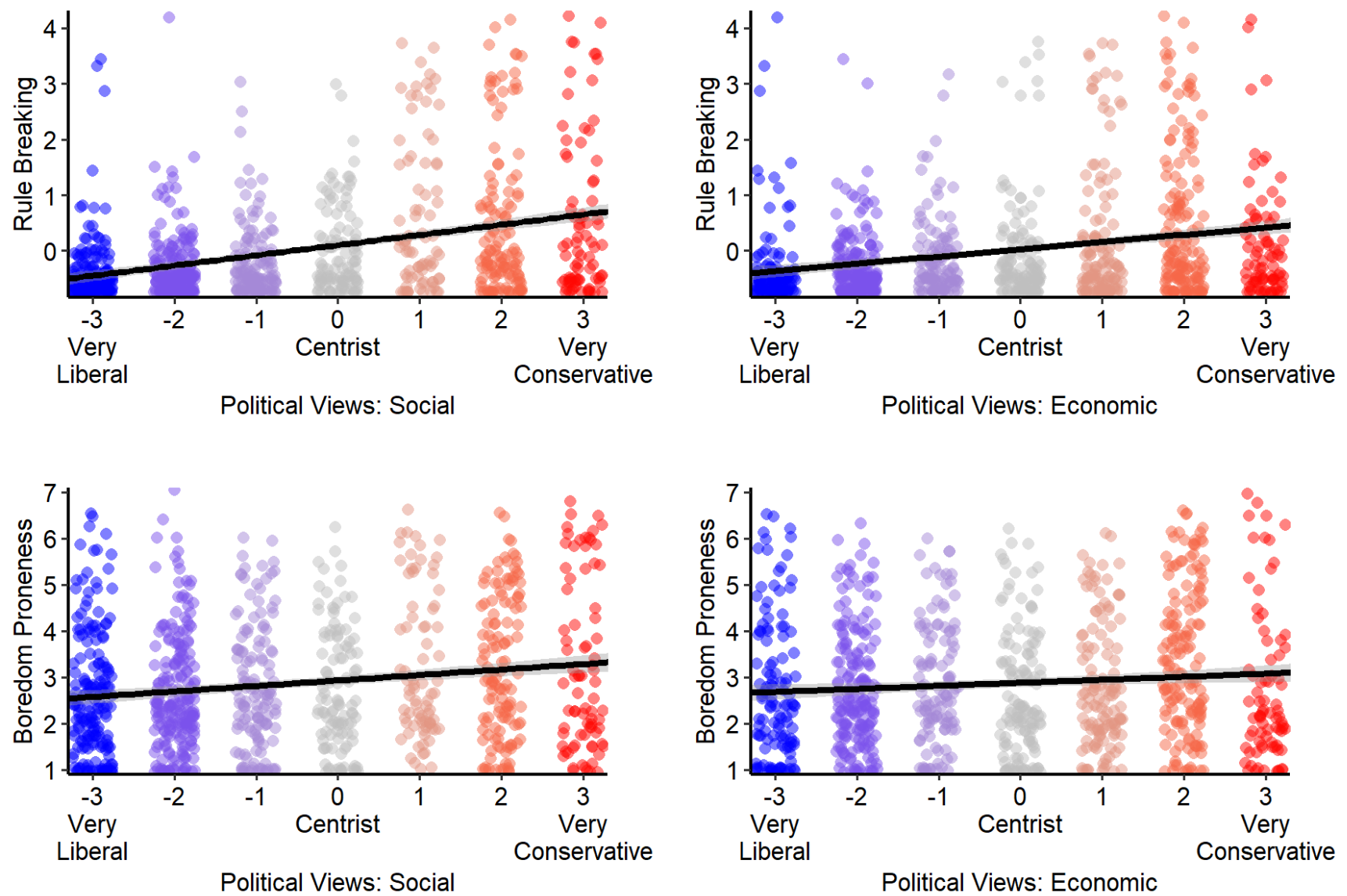

Figure 1. Bivariate correlations between political views (social views on the left and economic views to the right) and rule-breaking (top), and boredom proneness (bottom).

Next, to determine the extent to which our variables predicted rule-breaking, we conducted a step-wise hierarchical regression. In the first step age and gender were predictive of rule-breaking; both were negative predictors of rule-breaking, indicating that older people and females were less likely to rule-break. Next, we added boredom proneness, which was a strong positive predictor of rule-breaking. We then added political affiliations for both social and economic issues simultaneously. Results showed that only self-reported affiliation with social issues acted as a positive predictor of rule-breaking, indicating that endorsing stronger social conservative views was predictive of a higher incidence of rule-breaking. 
Finally, we conducted a moderation analysis to determine the extent to which political affiliation moderated the influence of boredom proneness on rule-breaking (Figure 2; Table 3). Results indicated that social, but not fiscal, conservatism positively moderated the association between boredom proneness and rule-breaking, indicating that the positive association between boredom proneness and rule-breaking was especially strong among social conservatives.

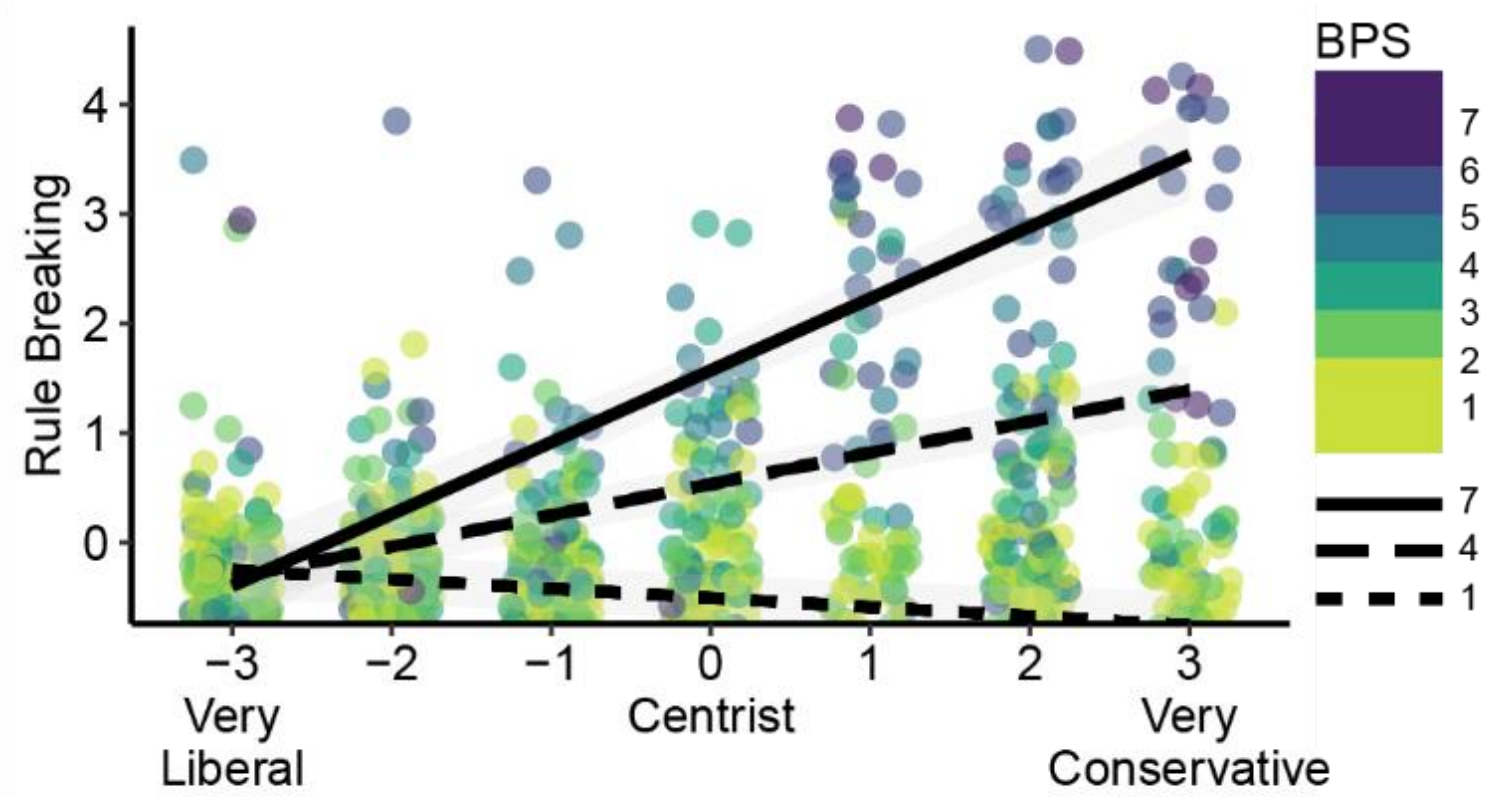

Political Views: Social

Figure 2. Political views plotted as a function of rule-breaking and boredom proneness (BP). 
Table 3. Hierarchical regression predicting rule-breaking.

\begin{tabular}{llcccc} 
Step 1 & & & & & \\
\hline & Predictors & Estimates & $95 \% \mathrm{CI}$ & $t$-value & $p$-value \\
& (Intercept) & 0.31 & $0.08-0.55$ & 2.62 & $0.009^{*}$ \\
Age & -0.01 & $-0.01-0.00$ & -2.93 & $0.003^{*}$ \\
& Gender & -0.15 & $-0.22--0.09$ & -4.53 & $<.001^{*}$ \\
& $\mathrm{R}^{2} / \mathrm{R}^{2}$ adjusted & $0.038 / 0.036$ & & &
\end{tabular}

\begin{tabular}{llcccc}
\hline Step 2 & & & & \\
\hline & Predictors & Estimates & $95 \% \mathrm{CI}$ & $t$-value & $p$-value \\
& (Intercept) & -1.04 & $-1.29--0.79$ & -8.13 & $<.001^{*}$ \\
& Age & 0 & $-0.01-0.00$ & -0.07 & 0.946 \\
Gender & -0.09 & $-0.15--0.04$ & -3.23 & $0.001^{*}$ \\
& BPS & 0.36 & $0.32-0.40$ & 17.95 & $<.001^{*}$ \\
& $\mathrm{R}^{2} / \mathrm{R}^{2}$ adjusted & $0.291 / 0.289$ & & &
\end{tabular}

\begin{tabular}{llcccc}
\hline Step 3 & & & & & \\
\hline & Predictors & Estimates & $95 \% \mathrm{CI}$ & $t$-value & $p$-value \\
& (Intercept) & -0.74 & $-0.98--0.50$ & -5.96 & $<.001^{*}$ \\
& Age & 0.00 & $-0.01-0.00$ & -1.22 & 0.224 \\
Gender & -0.07 & $-0.13--0.02$ & -2.72 & $0.007^{*}$ \\
BPS & 0.32 & $0.29-0.36$ & 16.8 & $<.001^{*}$ \\
Political Views: Social & 0.16 & $0.12-0.21$ & 7.30 & $<.001^{*}$ \\
& Political Views: Economic & -0.03 & $-0.07-0.02$ & -1.12 & 0.265 \\
& $\mathrm{R}^{2} / \mathrm{R}^{2}$ adjusted & $0.37 / 0.366$ & & & \\
& & & & &
\end{tabular}

Step 4

$\begin{array}{lcccc}\text { Predictors } & \text { Estimates } & 95 \% \mathrm{CI} & t \text {-value } & p \text {-value } \\ \text { (Intercept) } & -0.85 & -1.08--0.62 & -7.37 & <.001^{*} \\ \text { Age } & 0.00 & -0.01-0.00 & -1.36 & 0.174 \\ \text { Gender } & -0.06 & -0.11--0.01 & -2.18 & 0.03^{*} \\ \text { BPS } & 0.35 & 0.31-0.38 & 19.16 & <.001^{*} \\ \text { Political Views: Social } & -0.21 & -0.30--0.11 & -4.36 & <.001^{*} \\ \text { Political Views: Economic } & 0.07 & -0.03-0.16 & 1.40 & 0.162 \\ \text { BPS x PV: Social } & 0.12 & 0.10-0.15 & 8.62 & <.001^{*} \\ \text { BPS x PV: Economic } & -0.03 & -0.06-0.00 & -1.89 & 0.059 \\ \mathrm{R}^{2} / \mathrm{R}^{2} \text { adjusted } & 0.462 / 0.458 & & & \end{array}$

Note: $\mathrm{BPS}=$ Boredom Proneness Scale PV $=$ Political Views $;{ }^{*} p<0.05$ 


\section{Discussion}

In-the-moment feelings of boredom function as a call to action for more satisfying behavior (Elpidorou, 2018); which actions best address this call are likely moderated by other factors. Within the context of COVID-19 lockdowns - a breeding ground for state boredom (Caci et al., 2020; Chao et al., 2020; Yan et al., 2020)_this call for action has been associated with rule-breaking behavior among those high in trait boredom proneness (Boylan et al., 2020; Wolff et al., 2020). However, the factors that influence this relation between either state boredom or trait boredom proneness and rule-breaking remain unknown. Interestingly, the cultural landscape that humans occupy tends to channel state boredom's call towards behaviors that are symbolically satisfying: acts that offer a sense of meaning or agency (Van Tilburg \& Igou, 2019). One such symbolic response is the strengthened commitment to political ideologies, a strengthening that is evident following both induction of feelings of state boredom and in those prone to situational boredom (Van Tilburg \& Igou, 2016). Based on this, we hypothesized that trait boredom proneness would be strongly associated with rule-breaking behavior if this behavior is in line with one's political beliefs. Specifically, we hypothesized that the link between boredom proneness and rule-breaking would be strongest among conservatives (vs. liberals) whose ideology trends more towards oppositions to COVID-19 regulations (Corpuz et al., 2020). Our results support this hypothesis for social conservatism in particular: Although boredom proneness was generally associated with breaking social distancing rules, this association was most prominent as participants' social conservatism increased.

The relation between boredom - both state and trait boredom proneness - and conservative ideology may reflect a sense that, for some, the constraints of the pandemic have translated into a belief that their personal identity is threatened. That is, the prohibitions on 
personal action are seen as a threat to identity that in turn translates into a strong need to establish one's personal affiliations. Certainly, when people are induced to feel state boredom, they tend to strengthen their commitment to various ideological frameworks (Moynihan et al., 2021). Such "in-lab" manipulations of boredom may pale in comparison to the enduring challenges imposed by the rules of social distancing during the pandemic.

A key component of in-the-moment feelings of boredom is the threat to one's sense of agency (Elpidorou, 2020; Kahn, 2018). It may be the case that the relations observed here reflect both a need to establish meaning (i.e., through strengthened affiliations with political identity) and a need to re-establish agency. The two are likely related, with meaningful behaviors typically characterized as those deemed highly instrumental in the pursuit of high value goals (Van Tilburg \& Igou, 2013). Consistently, work in academic settings indicates that students are most bored when they find activities to be both low in value and lacking a sense of control (i.e., agency; Pekrun 2006). When lockdown constraints are applied, as happened at various times during the pandemic, agency is clearly curtailed. The tendency to break the rules imposed by such a lockdown clearly works to re-establish agency and when couched in terms of political ideology comes packaged with a ready-made justification. Clearly, future work of this kind would benefit from direct inclusion of metrics of the need for agency. Beyond agency, it will be important to explore the role played by meaning and meaning seeking in one's life, as these factors likely interact with the need to establish agency (Pereboom, 2014; Van Tilburg \& Igou, 2011, 2013).

Although trait boredom proneness was strongly correlated with more conservative views in both fiscal and social domains, the association was more pronounced for social issues (Figure 1). It may be the case that people find it easier to comprehend — and therefore endorse — what is 
meant by "social issues." It is also plausible that our participants resonated more with social issues given some of the polarizing debates of our time (e.g., anti-masks). Further research could use more detailed surveys of political attitudes to directly explore the association between boredom proneness and distinct aspects of political affiliation. What seems evident here is that there was a strong relation between high boredom proneness and strong adherence to conservative political ideology.

This work has implications for public policy. As we hinted at in our original paper (Boylan et al., 2020), it may be more productive to focus public messaging on what people can do as opposed to what they are constrained from doing. It is also clear that the politicization of public health policies can have negative effects, perhaps especially for vulnerable individuals (i.e., the boredom prone). It may be the case that interventions will have greater success when they emphasize collective attitudes and values (Ybarra \& Trafimow, 1998; Verplanken et al., 2009; Lindenberg \& Steg, 2013, 2007). That is, research has shown that priming either self-focus or collective values (cast in the context of environmentally friendly action intentions) predicts the weighting participants give to behavioral intentions in predictable ways. That is, social norms predicted behavioral intentions when collective values were primed (Verplanken et al., 2009; see also Verplanken \& Holland, 2002). Interventions that emphasize collective values (as opposed to personal affiliation with specific ideologies) may be more successful in promoting adherence to the rules of social distancing. It will be important that any attempt to promote adherence to the strictures of social distancing consider the degree to which aspects of the intervention are considered acceptable to the wider public (i.e., not simply appealing to one side of the political spectrum or another), as well as the efficacy of specific features of the intervention (i.e., 
components that are most likely to lead to success; see Rowe \& Frewer, 2000 for a detailed review of a wide variety of methods for public engagement in science-based policy making).

Regardless of the approach taken to promote adherence to the rules of social distancing, it is clear that what is needed is leadership that promotes social coherence and public health measures as opposed to politicizing the pandemic response. It may be helpful to develop ways for people to experience a sense of community while being mindful of the challenges of social distancing — promoting the notion that "we are all in this together." Such messaging may help people ground their sense of identity and control within a positive framework that promotes adaptive behaviors. Indeed, the desire to tie one's identity to a broader framework is a fundamental one (Baumeister, 1997). Adaptive responses to crises like the current pandemic are threatened when factors like boredom proneness push people to hunker down within identity silos that work against personal and societal well-being.

Funding: This study was funded by a Natural Sciences and Engineering Research Council of Canada Discovery grant to JD and a Social Sciences and Humanities Research Council of Canada grant to AS.

Conflict of Interest: There are no conflicts of interest to declare.

Ethical approval: All procedures performed in studies involving human participants were in accordance with the ethical standards of the institutional and/or national research committee and with the 1964 Helsinki declaration and its later amendments or comparable ethical standards.

Informed consent: Informed consent was obtained from all individual participants included in the study. 


\section{References}

Barari, S., Caria, S., Davola, A., Falco, P., Fetzer, T., Fiorin, S., ... \& Slepoi, F. R. (2020). Evaluating COVID-19 public health messaging in Italy: Self-reported compliance and growing mental health concerns. MedRxiv. https://doi.org/10.1101/2020.03.27.20042820

Baumeister, R. F. (1997). The self and society. In R.D. Ashmore \& L. Jussim (Eds.), Self and identity: Fundamental issues (pp. 191-217). New York: Oxford University Press.

Biolcati, R., Mancini, G., \& Trombini, E. (2018). Proneness to boredom and risk behaviors during adolescents' free time. Psychological Reports, 121, 303-323. https://doi: $10.1177 / 0033294117724447$

Boylan, J., Seli, P., Scholer, A. A., \& Danckert, J. (2020). Boredom in the COVID-19 pandemic: Trait boredom proneness, the desire to act, and rule-breaking. Personality and Individual Differences, 110387. https://doi.org/10.1016/j.paid.2020.110387

Caci, B., Miceli, S., Scrima, F., \& Cardaci, M. (2020). Neuroticism and Fear of COVID19. The Interplay Between Boredom, Fantasy Engagement, and Perceived Control Over Time. Frontiers in Psychology, 11, 2578. https://doi.org/10.3389/fpsyg.2020.574393

Carver, C. S., \& Scheier, M. (1990). Principles of self-regulation: Action and emotion. The Guilford Press.

Chao, M., Chen, X., Liu, T., Yang, H., \& Hall, B. J. (2020). Psychological distress and state boredom during the COVID-19 outbreak in China: the role of meaning in life and media use. European Journal of Psychotraumatology, 11, 1769379.

https://doi.org/10.1080/20008198.2020.176937 
Chin, A., Markey, A., Bhargava, S., Kassam, K. S., \& Loewenstein, G. (2017). Bored in the USA: Experience sampling and boredom in everyday life. Emotion, 17, 359-368. http://dx.doi.org/10.1037/emo0000232

Corpuz, R., D’Alessandro, S., Adeyemo, J., Jankowski, N., \& Kandalaft, K. (2020). Life history orientation predicts COVID-19 precautions and projected behaviors. Frontiers in Psychology, 11, 1857. https://doi.org/10.3389/fpsyg.2020.01857

Crowson, H. M. (2009). Are all conservatives alike? A study of the psychological correlates of cultural and economic conservatism. The Journal of Psychology, 143, 449-463. https://doi.org/10.3200/JRL.143.5.449-463

Dahlen, E. R., Martin, R. C., Ragan, K., \& Kuhlman, M. M. (2004). Boredom proneness in anger and aggression: Effects of impulsiveness and sensation seeking. Personality and Individual Differences, 37, 1615-1627. https://doi.org/10.1016/j.paid.2004.02.016

Danckert, J. (2019). Boredom: Managing the delicate balance between exploration and exploitation. In J. R. Velasco (Ed.) Boredom is in your mind: A shared PsychologicalPhilosophical Approach. (pp. 37-53). Springer, Cham.

Daschmann, E. C., Götz, T., \& Stupnisky, R. H. (2011). Testing the predictors of boredom at school: Development and validation of the precursors to boredom scales. British Journal of Educational Psychology, 81, 421-440. https://doi:10.1348/000709910X526038

DeCoster, J. (2007). Applied linear regression notes set 1. Retrieved from http://www.stat-help.com/notes.html. 
Eastwood, J. D., Frischen, A., Fenske, M. J., \& Smilek, D. (2012). The unengaged mind: Defining boredom in terms of attention. Perspectives on Psychological Science, 7, 482-495. doi:10.1177/1745691612456044

Elpidorou, A. (2020). Is boredom one or many? A functional solution to the problem of heterogeneity. Mind \& Language. https://doi:10.1111/mila.12282

Elpidorou, A. (2018). The bored mind is a guiding mind: Toward a regulatory theory of boredom. Phenomenology and the Cognitive Sciences, 17, 455-484. https://10.1007/s11097-0179515-1

Elpidorou, A. (2014). The bright side of boredom. Frontiers in Psychology, 5, 1245. https://doi.org/10.3389/fpsyg.2014.01245

Fahlman, S. A., Mercer, K. B., Gaskovski, P., Eastwood, A. E., \& Eastwood, J. D. (2009). Does a lack of life meaning cause boredom? Results from psychometric, longitudinal, and experimental analyses. Journal of Social and Clinical Psychology, 28, 307-340.

Farmer, R., \& Sundberg, N. D. (1986). Boredom proneness--the development and correlates of a new scale. Journal of Personality Assessment, 50, 4-17. https://doi.org/10.1207/s15327752jpa5001_2

Giambra, L. M., Camp, C. J., \& Grodsky, A. (1992). Curiosity and stimulation seeking across the adult life span: Cross-sectional and 6-to 8-year longitudinal findings. Psychology and Aging, 7, 150. 
Greenberg, J., \& Jonas, E. (2003). Psychological motives and political orientation--The left, the right, and the rigid: Comment on Jost et al. (2003). Psychological Bulletin, 129, 376382. https://doi:10.1037/0033-2909.129.3.376

Hart, P. S., Chinn, S., \& Soroka, S. (2020). Politicization and Polarization in COVID-19 News Coverage. Science Communication, 42, 679-697. https://doi:10.1177/1075547020950735

Heine, S. J., Proulx, T., \& Vohs, K. D. (2006). The meaning maintenance model: On the coherence of social motivations. Personality and Social Psychology Review, 10, 88-110.

Henningham, J. P. (1996). A 12-item scale of social conservatism. Personality and Individual Differences, 20, 517-519.

Isacescu, J., Struk, A. A., \& Danckert, J. (2017). Cognitive and affective predictors of boredom proneness. Cognition and emotion, 31, 1741-1748.

https://doi.org/10.1080/02699931.2016.1259995

Jost, J. T., \& Amodio, D. M. (2012). Political ideology as motivated social cognition: Behavioral and neuroscientific evidence. Motivation and Emotion, 36, 55-64. https://doi:10.1007/s11031-011-9260-7

Jost, J. T., Napier, J. L., Thorisdottir, H., Gosling, S. D., Palfai, T. P., \& Ostafin, B. (2007). Are needs to manage uncertainty and threat associated with political conservatism or ideological extremity? Personality and Social Psychology Bulletin, 33, 989-1007. https://doi:10.1177/0146167207301028

Kahn, L. (2018). Boredom and the need for agency. Ph.D. Dissertation, University of Oregon. 
Kılıç, A., Van Tilburg, W. A. P., \& Igou, E. R. (2020). Risk-taking increases under boredom. Journal of Behavioral Decision Making, 33, 257-269.

https://doi.org/10.1002/bdm.2160

Klein, N. (2017). Prosocial behavior increases perceptions of meaning in life. Journal of Positive Psychology, 12, 354-361. https://doi.org/10.1080/17439760.2016.1209541

Lindenberg, S., \& Steg, L. (2007). Normative, gain and hedonic goal frames guiding environmental behaviour. Journal of Social Issues, 63, 117-137. https://doi.org/10.1111/j.15404560.2007.00499.x

Lindenberg, S., \& Steg, L. (2013). Goal-framing theory and norm-guided environmental behaviour. In H. van Trijp (Ed.), Encouraging sustainable behaviour (pp.37-54). New York, NY: Psychology Press.

McGregor, I., Prentice, M., \& Nash, K. (2013). Anxious uncertainty and reactive approach motivation (RAM) for religious, idealistic, and lifestyle extremes. Journal of Social Issues, 69, 537-563.

Moynihan, A. B., Igou, E. R., \& Van Tilburg, W. A. P. (2021). Existential escape of the bored: A review of meaning-regulation processes under boredom. European Review of Social Psychology. https://doi.org/10.1080/10463283.2020.1829347

Mugon, J., Struk, A., \& Danckert, J. (2018). A failure to launch: Regulatory modes and boredom proneness. Frontiers in Psychology, 9, 1126. https://doi.org/10.3389/fpsyg.2018.01126

Pawlak, M., Kruk, M., \& Zawodniak, J. (2020). Investigating individual trajectories in experiencing boredom in the language classroom: The case of 11 Polish students of 
English. Language Teaching Research, 1362168820914004.

https://doi.org/10.1177/1362168820914004

Pekrun, R. (2006). The control-value theory of achievement emotions: Assumptions, corollaries, and implications for educational research and practice. Educational Psychology Review, 18, 315-341. https://doi:10.1007/s10648-006-9029-9

Pekrun, R., Goetz, T., Daniels, L. M., Stupnisky, R. H., \& Perry, R. P. (2010). Boredom in achievement settings: Exploring control-value antecedents and performance outcomes of a neglected emotion. Journal of Educational Psychology, 102, 531-549.

https://doi:10.1037/a0019243

Pekrun, R., Hall, N. C., Goetz, T., \& Perry, R. P. (2014). Boredom and academic achievement: Testing a model of reciprocal causation. Journal of Educational Psychology, 106, 696-710. https://doi:10.1037/a0036006

Pereboom, D. (2014). Free will, agency, and meaning in life. Oxford University Press.

Pfattheicher, S., Lazarević, L. B., Westgate, E. C., \& Schindler, S. (2020). On the relation of boredom and sadistic aggression. Journal of Personality and Social Psychology.

Routledge, C., Arndt, J., Wildschut, T., Sedikides, C., Hart, C. M., Juhl, J., Vingerhoets, A. J. J. M. \& Schlotz, W. (2011). The past makes the present meaningful: Nostalgia as an existential resource. Journal of Personality and Social Psychology, 101, 638-652.

Routledge, C., Arndt, J., Sedikides, C., \& Wildschut, T. (2008). A blast from the past: The terror management function of nostalgia. Journal of Experimental Social Psychology, 44, 132-140. https://doi.org/10.1016/j.jesp.2006.11.001 
Rowe, G., \& Frewer, L. J. (2000). Public participation methods: A framework for evaluation. Science, Technology, \& Human Values, 25(1), 3-29. https://doi.org/10.1177/016224390002500101

Smith, C. A., \& Ellsworth, P. C. (1985). Patterns of cognitive appraisal in emotion. Journal of Personality and Social Psychology, 48, 813-838.

Spears, R., Scheepers, D., Jetten, J., Doosje, B., Ellemers, N., \& Postmes, T. (2004). Entitativity, group distinctiveness, and social identity: Getting and using social structure. In V. Yzerbyt, C. M. Judd, \& O. Corneille (Eds.), The psychology of group perception: Perceived variability, entitativity, and essentialism (pp. 293-318). New York, NY: Psychology Press.

Struk, A. A., Carriere, J. S., Cheyne, J. A., \& Danckert, J. (2017). A short boredom proneness scale: Development and psychometric properties. Assessment, 24, 346-359. https://doi:10.1177/1073191115609996

Tam, K. Y. Y., Van Tilburg, W. A. P., \& Chan, C. S. (in press). What is boredom proneness? A comparison of three operationalizations. Journal of Personality. https://doi:10.1111/jopy.12618

Tulis, M., \& Fulmer, S. M. (2013). Students' motivational and emotional experiences and their relationship to persistence during academic challenge in mathematics and reading. Learning and Individual Differences, 27, 35-46. https://doi:10.1016/j.lindif.2013.06.003

Van Tilburg, W. A. P., \& Igou, E. R. (2011). On boredom and social identity: A pragmatic meaning-regulation approach. Personality and Social Psychology Bulletin, 37, 16791691. https://doi:10.1177/0146167211418530 
Van Tilburg, W. A. P., \& Igou, E. R. (2013). On the meaningfulness of behavior: An expectancy $x$ value approach. Motivation and Emotion, 37, 373-388. https://doi:10.1007/s11031012-9316-3

Van Tilburg, W. A. P., \& Igou, E. R. (2016). Going to political extremes in response to boredom. European Journal of Social Psychology, 46, 687-699.

https://doi.org/10.1002/ejsp.2205

Van Tilburg, W. A. P., \& Igou, E. R. (2017). Can boredom help? Increased prosocial intentions in response to boredom. Self and Identity, 16, 82-96.

https://doi.org/10.1080/15298868.2016.1218925

Van Tilburg, W. A. P., Igou, E. R., \& Sedikides, C. (2013). In search of meaningfulness: Using nostalgia as an antidote to boredom. Emotion, 13, 450-461. https://doi.org/10.1037/a0030442

Van Tilburg, W. A. P., Igou, E. R., Maher, P. J., Moynihan, A. B., \& Martin, A. (2019). Bored like hell: Religiosity reduces boredom and tempers the quest for meaning. Emotion, 19, 255-269. https://doi.org/10.1037/emo0000439

Van Tilburg, W. A. P., \& Igou, E. R. (2019). The unbearable lightness of boredom: A pragmatic meaning-regulation hypothesis. In J. Ros Velasco (Ed.), Boredom is in your Mind (pp. 11-35). Springer.

Verplanken, B., \& Holland, R. W. (2002). Motivated decision making: Effects of activation and self-centrality of values on choices and behavior. Journal of Personality and Social Psychology, 82, 434-447. https://doi.org/10.1037/0022-3514.82.3.434 
Verplanken, B., Trafimow, D., Khusid, I. K., Holland, R. W., \& Steentjes, G. M. (2009). Different selves, different values: Effects of self-construals on value activation and use. European Journal of Social Psychology, 39, 909-919. https://doi.org/10.1002/ejsp.587

Westgate, E. C., \& Wilson, T. D. (2018). Boring thoughts and bored minds: The MAC model of boredom and cognitive engagement. Psychological Review, 125, 689. https://doi.org/10.1037/rev0000097

Wolff, W., Martarelli, C. S., Schüler, J., \& Bieleke, M. (2020). High boredom proneness and low trait self-control impair adherence to social distancing guidelines during the COVID-19 pandemic. International Journal of Environmental Research and Public Health, 17, 5420. https://doi:10.3390/ijerph17155420

Yan, L., Gan, Y., Ding, X., Wu, J., \& Duan, H. (2020). The relationship between perceived stress and emotional distress during the COVID-19 outbreak: Effects of boredom proneness and coping style. Journal of Anxiety Disorders, 102328. https://doi.org/10.1016/j.janxdis.2020.102328

Ybarra, O., \& Trafimow, D. (1998). How priming the private self or collective self affects the relative weights of attitudes and subjective norms. Personality and Social Psychology Bulletin, 24, 362-370. 